\title{
Brush Border Disaccharidases in Dog Kidney and Their Spatial Relationship to Glucose Transport Receptors
}

\author{
Melvin Silverman \\ From the Department of Medicine, Division of Nephrology, Toronto General \\ Hospital, Toronto M.5G IL7, Ontario, Canada
}

A в S T R A C T The localization of disaccharidases in kidney has been studied by means of the multiple indicator dilution technique. A pulse injection of a solution containing Evans blue dye (plasma marker), creatinine (extracellular marker), and a ${ }^{14} \mathrm{C}$-labeled disaccharide (lactose, sucrose, maltose, and $\alpha \alpha$-trehalose), is made into the renal artery of an anesthetized dog, and the outflow curves are monitored simultaneously from renal venous and urine effluents. Lactose and sucrose have an extracellular distribution. Trehalose and maltose remain extracellular from the postglomerular circulation. About $75 \%$ of filtered tracer maltose or trehalose is extracted by the luminal surface of the nephron. Thin-layer chromatography of urine samples shows that all of the excreted ${ }^{14} \mathrm{C}$ radiolabel is in the form of the injected disaccharide. Following the administration of phlorizin, all of the filtered radioactivity is recoverable in the urine, but chromatography of the urine samples now reveals that there is a significant excretion of $\left[{ }^{14} \mathrm{C}\right]$ glucose, approximating the amount previously extracted under control conditions (in the absence of phlorizin). It has been verified that no hydrolysis of maltose or trehalose to their constituent glucose subunits occurred during the transit of tracer between the point of injection (renal artery), and the point of filtration (glomerular basement membrane). Similarly, after addition of $\left[{ }^{14} \mathrm{C}\right]$ disaccharides to fresh urine there is no chromatographically recoverable $\left[{ }^{14} \mathrm{C}\right]$ glucose.

It is concluded that there exist $\alpha$-glucosidases with maltase and trehalase activity along the brush border of

This work was presented at the International Society of Nephrology, October 1972, Mexico City, Mexico, and the Canadian Society for Clinical Investigation, January 1973, Edmonton, Canada. A preliminary report of this work has been published in abstract form (1).

Dr. Silverman is a scholar of the Medical Research Council of Canada.

Received for publication 13 April 1973 and in revised form 8 June 1973. the proximal tubule and that these disaccharidases are located spatially superficial to the glucose transport receptors.

\section{INTRODUCTION}

The disaccharidases maltase and trehalase have been demonstrated in membrane fractions prepared from rabbit (2-4) and rat (5) kidney, but the functional significance of these enzymes in the kidney remains unknown.

It was suggested several years ago (6) that trehalase may play a role in the active transport of glucose by the intestine as well as the kidney. In the intestine, there is evidence that trehalase is located in the mucosal brush border, spatially superficial to the glucose transport mechanism (7-9). This experimental finding, together with other data summarized by Semenza and Rikova (10), argues against the participation of trehalase in the active transport of glucose. However, in more recent studies (11), using everted sacs of small intestine, new data have been obtained which imply the existence of disaccharidases (maltase, trehalase, sucrase), internal (serosal) as well as external (mucosal) to the glucose transport receptors. Also, papain digestion of kidney brush border membranes (3) releases maltase into the supernate but leaves trehalase bound to the membrane matrix.

On the basis of these data, the suggestion that trehalase plays a role in the intestinal and renal transport of glucose remains a viable hypothesis.

We have previously described $(12,13)$ how the multiple indicator dilution technique can be adapted in dog kidney to differentiate between chemical interactions occurring at the luminal (brush border) surface from events taking place at the antiluminal (basal and lateral) membrane. The details of our method for distinguishing between the opposing surfaces of the nephron have been 
given in the previously mentioned publications $(12,13)$ and are described briefly in the Methods section below.

The present study was undertaken to investigate the nature of the interaction between disaccharides, in particular trehalose and maltose, with the luminal and antiluminal surfaces of the nephron and to determine the relationship (if any) to the glucose transport mechanism.

\section{METHODS}

The surgical and experimental procedures used in these studies have been described in detail in previous publications (12-14). Briefly, a closed arterial injection of a mixture of indicators (total volume of $0.35-0.45 \mathrm{ml}$ ) is made into the left renal artery of an anesthetized mongrel dog, and timed serial samples are obtained simultaneously from left renal vein (30 samples in 15 or $30 \mathrm{~s}$ ) and from right and left ureters (30 urine samples in 5 or $10 \mathrm{~min}$ ). Appropriate internal standards are prepared in blood and urine collected prior to each experimental run. By analyzing the internal standards along with the unknown samples in blood and urine the concentration of the injected indicators is determined. The data are expressed as fractional recovery (of the total amount injected) per milliliter of whole blood, versus time, for the renal venous effluent, and as fractional recovery versus time in the urine effluent. Recirculation corrections as well as methods for calculation of blood flow, mean transit time and fractional tracer reabsorption from the urine have been previously described $(12,13)$.

It is worth noting that the rationale for using our method to differentiate luminal and antiluminal events is based upon having a valid reference marker for the extracellular space. In the case of the dog kidney it turns out that creatinine can serve as such a marker. Then, if a test solute has a transit pattern in either the renal venous or urine effluent that superimposes on the corresponding creatinine curve its distribution must be identical to that of creatinine, namely extracellular. If, on the other hand, the transit pattern of a test solute emerges in the renal vein effluent so that in the first few samples the recovery is less than that of simultaneously injected creatinine, such an observation implies that the test solute has available an excess volume of distribution from the postglomerular capillary circulation compared to creatinine. This means that the test solute is either binding to or crossing the antiluminal surface of the nephron, from the postglomerular circulation.

Similarly, when the urine outflow pattern for a test solute emerges symmetrical to but lower than that of simultaneously filtered creatinine, then a fraction of the test solute has been extracted by the luminal surface somewhere between the point of filtration and the point of urine collection. Because sugar reabsorption has been localized to the proximal tubule (15) the luminal extraction of radiolabeled sugars observed in our studies must reflect events occurring at the level of the brush border membrane of the proximal tubule.

Finally, in order to completely account for the intrarenal distribution and metabolism of radiolabeled disaccharides, we have combined the results of the multiple indicator dilution technique with thin-layer chromatography of individual renal venous and urine samples. By so doing, all of the injected ${ }^{14} \mathrm{C}$-labeled disaccharides have been identified in the venous and urine effluents either in their original injected form or as the appropriate constituent monosaccharides.

Injection solutions were prepared in $4 \mathrm{ml}$ of isotonic saline to contain $15 \mathrm{mg} / \mathrm{ml}$ creatinine (Pfanstiehl, Waukegan,
I11.), and 6.25 or $12.5 \mu \mathrm{Ci} / \mathrm{ml}$ of the following radiolabeled test disaccharides: $\left[{ }^{14} \mathrm{C}\right]$ sucrose and $\left[{ }^{14} \mathrm{C}\right] \alpha \alpha$-trehalose, specific activity $360 \mathrm{mCi} / \mathrm{mM}$ (ICN Chemical and Radioisotopes Div., Irvine, Calif.) ; $\left[1{ }^{14} \mathrm{C}\right]$ lactose $(14.9 \mathrm{mCi} / \mathrm{mM})$; and $\left[\mathrm{U}-{ }^{14} \mathrm{C}\right]$ maltose $(7 \mathrm{mCi} / \mathrm{mM})$ (Amersham/Searle Corp., Arlington Heights, Ill.). $1 \mathrm{ml}$ of this solution was removed and saved for urine standards. T1824 (Evan blue dye), (Matheson Coleman \& Bell, Norwood, Ohio) was added to the remaining $3 \mathrm{ml}$ to make a concentration of $2.5 \mathrm{mg} / \mathrm{ml}$. The solution containing T1824 was used for injection and for preparing blood standards.

Determinations of arterial whole blood and plasma glucose concentrations were made at the beginning and end of each experimental run. (Glucostat, Worthington Biochemical Corp., Freehold, N. J.). Analytical determinations of T1824, creatinine, and radioactivity were made as previously described (12).

Blood pressure, blood $\mathrm{pH}, \mathrm{Po}_{2}$ and $\mathrm{PCO}_{2}$ were determined for each run. At the end of each experiment, the kidney was removed, weighed, and examined for any gross abnormality.

All the chemical dilutions were performed using automatic dilutors whose reproducibility is $0.6 \%$ (ADD System, Fisons Scientific Apparatus Ltd., Loughborough, Leicestershire, England) and the reproducibility of each experimental data point is better than $3 \%$.

Thin-layer chromatography was carried out on silica gel plates (Eastman Kodak, Rochester, N. Y.). Chromatography was performed on alcohol filtrates of samples from blood, urine, injection solutions, and unlabeled sugar standards of glucose, trehalose, and maltose. For trehalose the solvent was a mixture of $n$-butanol, ethanol, water, and ammonium hydroxide in a ratio of $45: 5: 49: 1$. The chromatograms were run for $3-4 \mathrm{~h}$ (10 cm migration of solvent front) and spots were visualized with periodate potassium permanganate (British Drug Houses Ltd., Poole, Dorset, England).

Radioactivity was recoverable only in areas corresponding to the disaccharide or glucose. For a given sample the percentage of ${ }^{14} \mathrm{C}$ radioactivity in the form of the intact disaccharide or constituent monosaccharide was obtained as follows: First the chromatographic spots corresponding to the origin, the disaccharide, and the monosaccharide were extracted. Then the eluted spots were added to $10 \mathrm{ml}$ of liquid scintillation fluid and counted in a beta liquid scintillation spectrometer. Quench corrections were made using a channels ratio technique. The relative proportion of $\mathrm{dpm}$ representing either the di- or monosaccharide can then be expressed as a percentage of the total recoverable radioactivity, using the origin as a blank.

\section{RESULTS}

Typical outflow or transit patterns for radiolabeled lactose, sucrose, maltose, and $\alpha \alpha$-trehalose are shown in Figs. 1-4, respectively. Table I shows some quantitative data relating recoveries and mean transit times for the test disaccharides compared to the extracellular reference creatinine. Inspection of the renal vein data reveals that the curves for the ${ }^{14} \mathrm{C}$-labeled disaccharides and that of simultaneously injected creatinine are superimposable on one another. This indicates that these substances have an extracellular distribution from the postglomerular circulation.

Inspection of the urine data shows that sucrose and lactose are superimposable on the creatinine curve. This 



Figure 1 Renal vein and urine outflow curves for T1824, creatinine, and $\left[{ }^{14} \mathrm{C}\right]$ lactose.

means that the amount of filtered sucrose and lactose as well as their intratubular volume of distribution are identical to creatinine. In other words, there is no interaction of either sucrose or lactose with the luminal surface of the nephron. In contrast, the urine recovery of ${ }^{14} \mathrm{C}$-labeled maltose and $\alpha \alpha$-trehalose (Figs. 3, 4) is much less than that of creatinine. Since these disaccharides are filtered at the glomerulus to the same extent as creatinine, $75 \%$ (see Table I) of the tracers must have been extracted by the luminal surface of the nephron.
TABLE I

Data from Indicator Dilution Experiments

\begin{tabular}{|c|c|c|c|c|}
\hline & \multirow{2}{*}{$\begin{array}{l}\text { Arterial } \\
\text { plasma } \\
\text { glucose }\end{array}$} & \multicolumn{2}{|c|}{ Renal vein } & \multirow{2}{*}{$\frac{\text { Urine }}{\left[1-\left(\Sigma^{14} \mathrm{C} / \Sigma \mathrm{Cr}\right)\right] \S}$} \\
\hline & & $\Sigma^{1+} \mathrm{C} / \Sigma \mathrm{Cr} *$ & $\mathrm{t} 11 \overline{\mathrm{C}} / \mathrm{t} \mathrm{c}_{\mathrm{r}} \bar{\ddagger}$ & \\
\hline & $\mathrm{mg} / 100 \mathrm{ml}$ & & & \\
\hline \multirow[t]{3}{*}{ Sucrose } & 65 & 1.04 & 0.99 & 0.00 \\
\hline & 52 & 1.03 & 0.99 & 0.07 \\
\hline & 74 & 1.06 & 0.98 & - \\
\hline \multirow[t]{3}{*}{ Lactose } & 104 & 0.83 & 0.94 & 0.01 \\
\hline & 98 & 1.04 & 0.98 & 0.08 \\
\hline & 71 . & 1.10 & 0.98 & 0.00 \\
\hline \multirow[t]{6}{*}{ Trehalose } & 66 & 0.95 & 0.99 & 0.89 \\
\hline & 62 & 1.06 & 0.98 & 0.78 \\
\hline & 114 & 1.12 & 1.04 & 0.79 \\
\hline & 111 & 0.90 & 1.03 & 0.76 \\
\hline & 81 & 1.07 & 0.98 & 0.67 \\
\hline & 75 & 1.04 & 0.97 & 0.91 \\
\hline \multirow[t]{3}{*}{ Maltose } & 108 & 0.95 & 0.97 & 0.79 \\
\hline & - & 0.92 & 0.99 & 0.66 \\
\hline & 75 & 0.98 & 0.98 & 0.84 \\
\hline
\end{tabular}

$* \Sigma^{14} \mathrm{C} / 2 \mathrm{Cr}=$ relative recoveries of $\left[{ }^{14} \mathrm{C}\right]$ disaccharide and creatinine in renal vein effluent.

$\ddagger \overline{\mathrm{t}}_{1 \mathrm{c}} \mathrm{c} / \overline{\mathrm{t}}_{\mathrm{r}}=$ relative mean transit times of [ $\left.{ }^{14} \mathrm{C}\right]$ disaccharide and creatinine in renal vein effluent. Mean transit times corrected for catheter effect.

$\delta\left[1-\left(\Sigma^{14} \mathrm{C} / \Sigma \mathrm{Cr}\right)\right]=$ fractional extraction of $\left[{ }^{14} \mathrm{C}\right]$ disaccharide by the luminal surface of nephron.

Previous studies (12) have shown that low systemic doses of phlorizin can completely inhibit glucose transport at the brush border surface of the proximal tubule. Therefore it was of interest to see what effect phlorizin would have on the "interaction" of trehalose and maltose with the luminal surface.
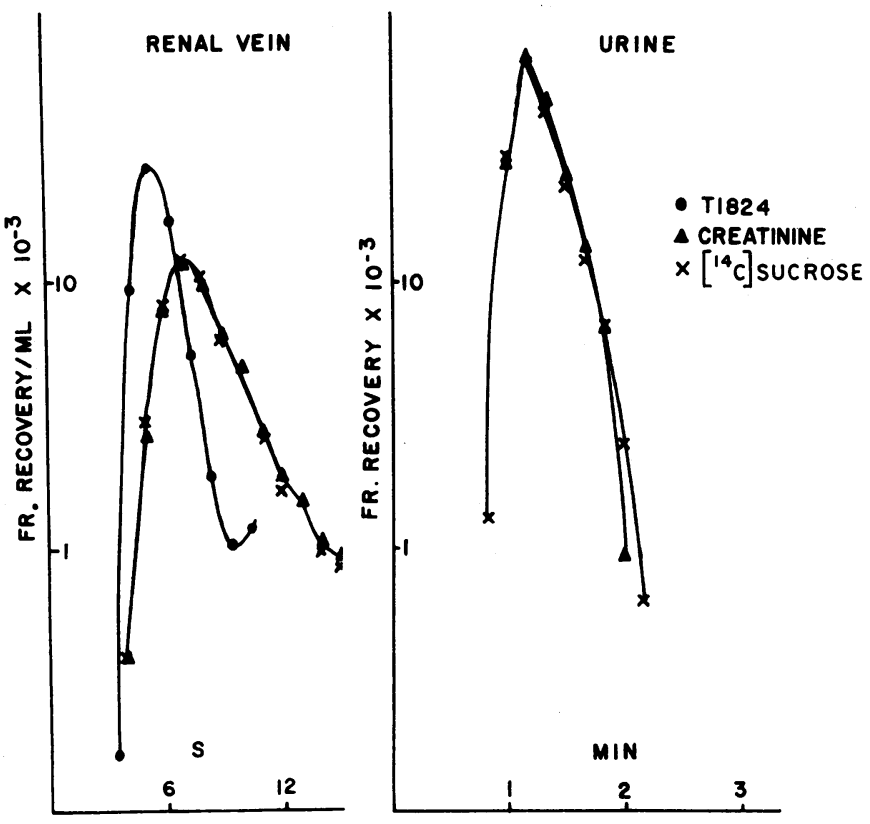

Figuke 2 Renal vein and urine outflow curves for T1824, creatinine, and $\left[{ }^{14} \mathrm{C}\right]$ sucrose. 


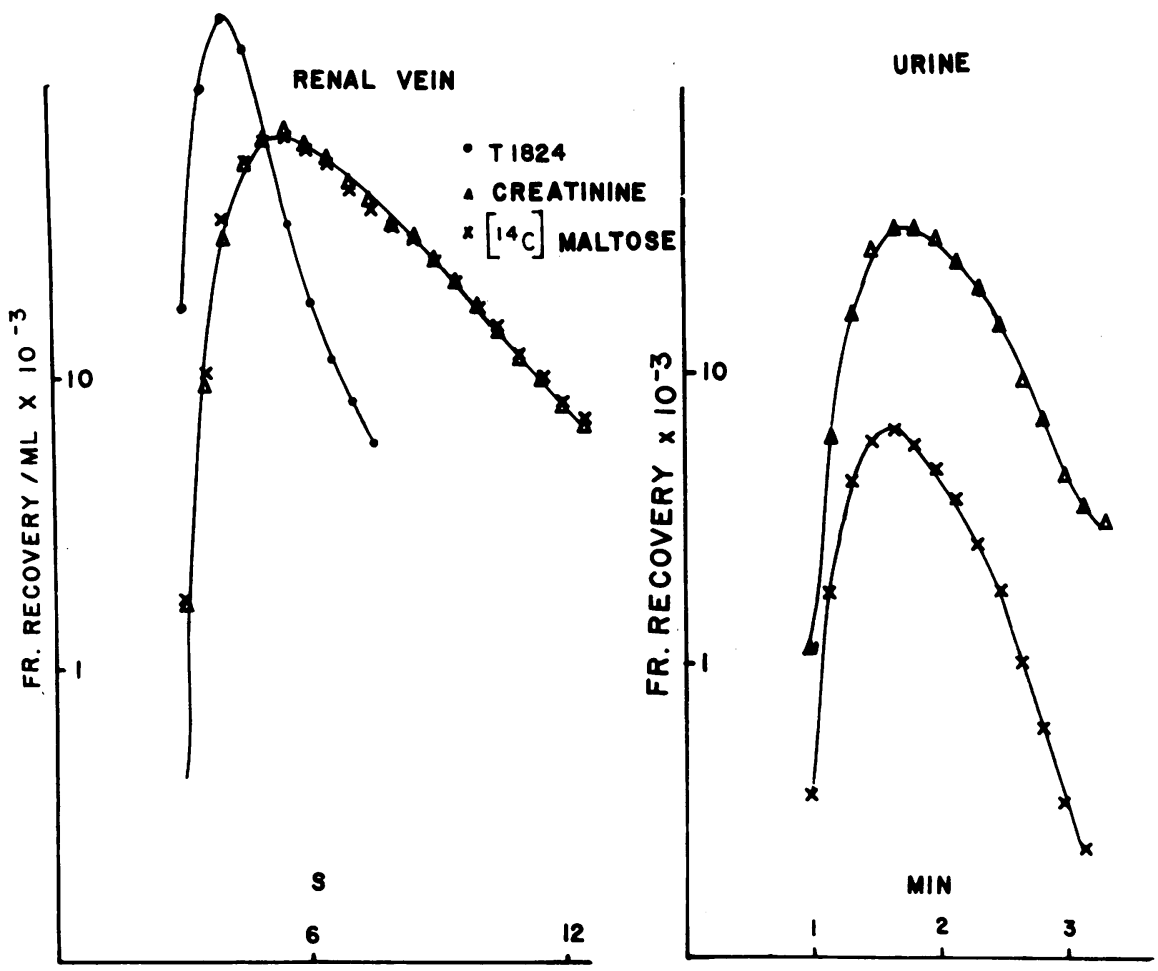

FIGURE 3 Renal vein and urine outflow curves for T1824, creatinine, and $\left[{ }^{14} \mathrm{C}\right]$ maltose.
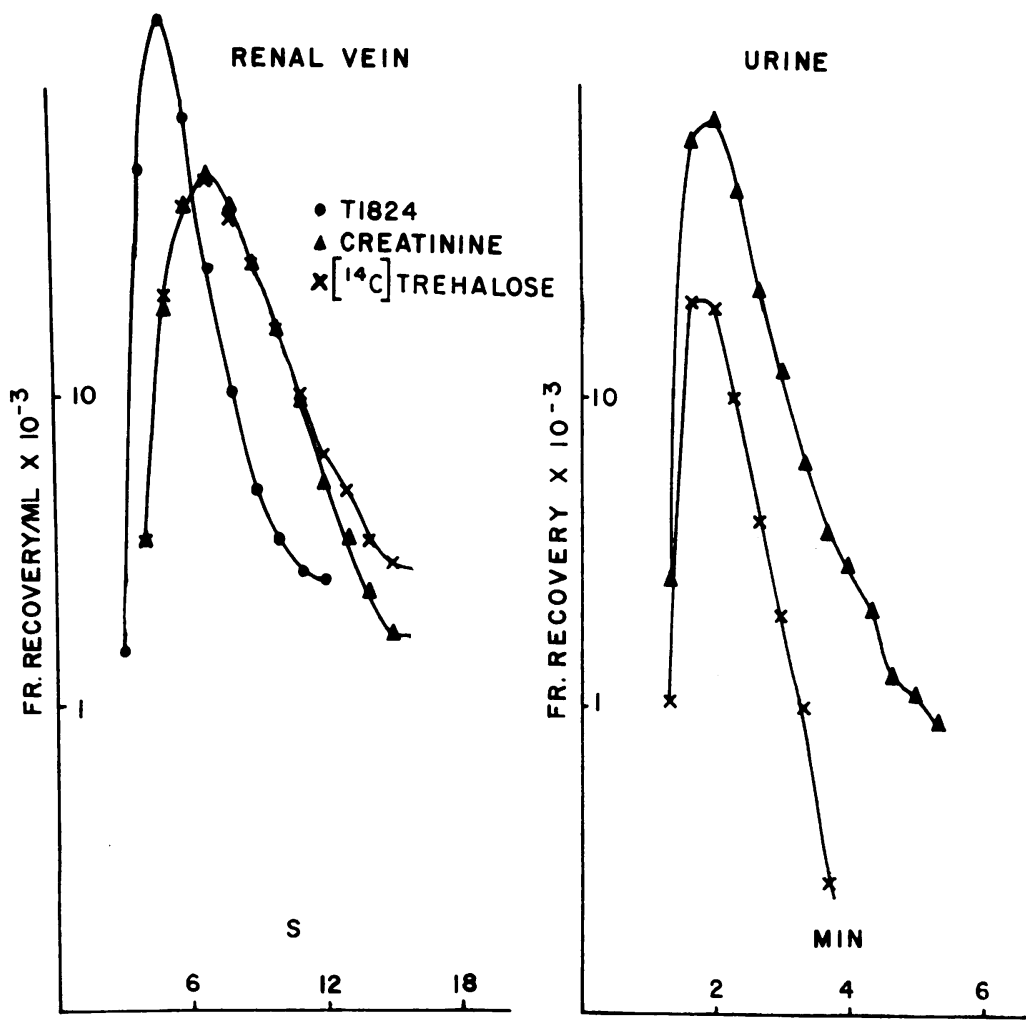

FigliRe 4 Renal vein and urine outflow curves for T1824, creatinine, and $\left[{ }^{14} \mathrm{C}\right] \alpha \alpha$-trehalose. 


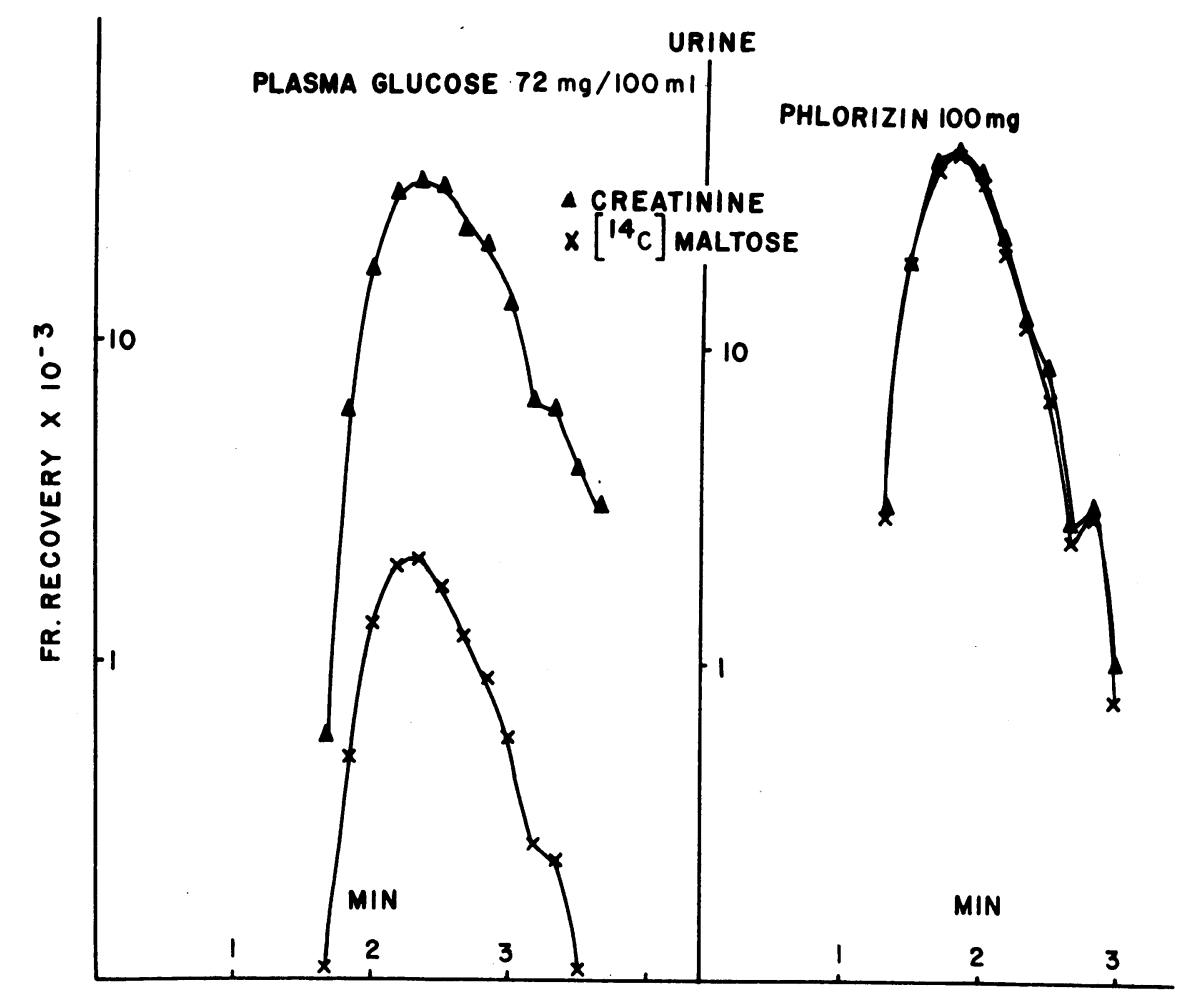

Figure 5 Urine outflow curves for creatinine and $\left[{ }^{14} \mathrm{C}\right]$ maltose before and after the administration of phlorizin.

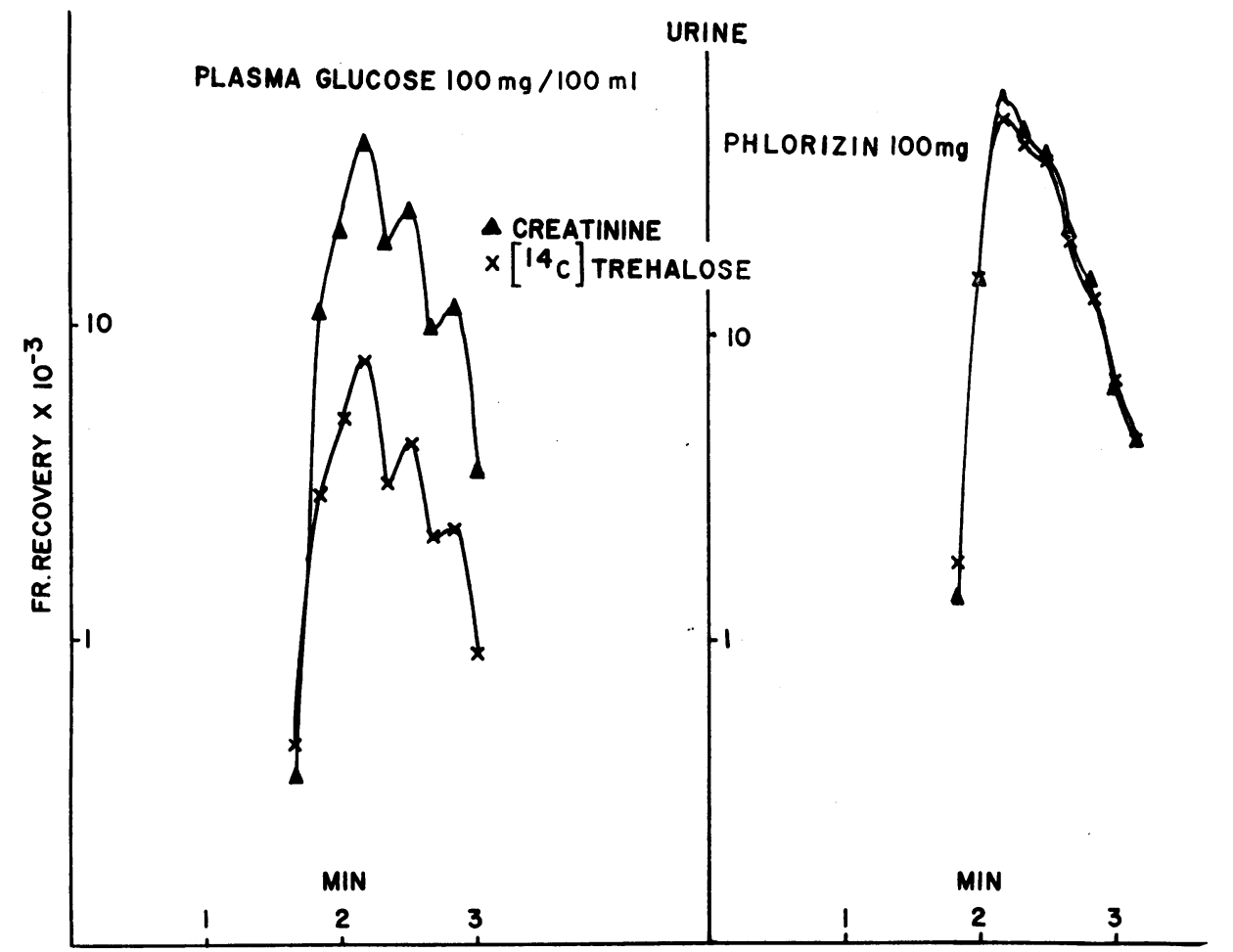

Figure 6 Urine outflow curves for creatinine and $\left[{ }^{14} \mathrm{C}\right] \alpha \alpha$-trehalose before and after the administration of phlorizin. 
TABLE II

Urine Excretion of $\left[{ }^{11} \mathrm{C}\right] \alpha \alpha$-Trehalose

\begin{tabular}{|c|c|c|c|c|c|c|c|}
\hline & \multirow{2}{*}{$\begin{array}{l}\text { Total }\left[{ }^{14} \mathrm{C}\right]- \\
\text { trehalose } \\
\text { filtered* }\end{array}$} & \multirow[b]{2}{*}{$\begin{array}{l}\text { Total }{ }^{14} \mathrm{C} \\
\text { excreted }\end{array}$} & \multicolumn{2}{|c|}{ Chromatography of excreted ${ }^{14} \mathrm{C}$} & \multirow{2}{*}{\begin{tabular}{l}
$\mathrm{C}$ \\
\multicolumn{2}{c}{${ }^{14} \mathrm{C}$} \\
reabsorbed
\end{tabular}} & \multirow{2}{*}{$\begin{array}{l}\%^{14} \mathrm{C} \\
\text { excreted as } \\
\text { trehalose }\end{array}$} & \multirow{2}{*}{$\begin{array}{c}\%{ }^{14} \mathrm{C} \\
\text { excreted as } \\
\text { glucose }\end{array}$} \\
\hline & & & $\begin{array}{c}\% \text { as } \\
\text { trehalose }\end{array}$ & $\begin{array}{l}\% \text { as } \\
\text { glucose }\end{array}$ & & & \\
\hline Control & 0.14 .3 & 0.0 .31 & 97 & 3 & 79 & 21 & () \\
\hline Phlorizin & 0.199 & 0.182 & 48 & 52 & 9 & 44 & 47 \\
\hline Control & 0.172 & 0.028 & 95 & 5 & 84 & 15 & 1 \\
\hline Phlorizin & 0.170 & 0.162 & 32 & 68 & 5 & 30 & 65 \\
\hline Control & 0.107 & 0.010 & 95 & 5 & 91 & 9 & 0 \\
\hline Phlorizin & 0.077 & 0.054 & 7 & 93 & 30 & 5 & 65 \\
\hline
\end{tabular}

* Expressed as a fraction of amount injected into renal artery.

A series of experiments were designed in which two runs were performed. First a control was obtained (blood and urine), in which either ${ }^{14} \mathrm{C}$-labeled trehalose or maltose was injected along with T1824 and creatinine. Following this, phlorizin was administered systemically in a dose of $100 \mathrm{mg}$ (dissolved in $50 \mathrm{ml}$ of $20 \mathrm{mM}$ sodium bicarbonate). After approximately $\frac{1}{2} \mathrm{~h}$, a second run was performed with the same injection solution as that used in the control. This low dose of phlorizin had no effect on the renal vein outflow patterns of maltose or $\alpha \alpha$-trehalose. The urine outflow curves for these experiments are shown in Figs. 5 and 6 and the data are presented in Tables II and III (column two). Inspection of the outflow curves shows that phlorizin increases the excretion of the carbon-14 label and, in effect, completely inhibits the fractional extraction of the filtered radiolabel by the luminal surface of the nephron.

There are only two ways to explain these results: (1) either the disaccharides, maltose and trehalose are reabsorbed by a phlorizin sensitive mechanism (i.e. by the transport system for D-glucose) or (2) somewhere between the point of injection (renal artery), and the phlorizin sensitive D-glucose transport sites (brush border of proximal tubule), the disaccharides are hydrolyzed into their constituent monosaccharides and are then reabsorbed as D-glucose.

To distinguish between these possibilities it was first necessary to show that dog blood and urine contain no maltase or trehalase activity. Chromatography of whole blood incubated with $\left[{ }^{14} \mathrm{C}\right]$ trehalose reveals no breakdown to $\left[{ }^{14} \mathrm{C}\right]$ glucose. Dog blood does exhibit maltase activity; however, by adding labeled maltose to whole blood and chromatographing at different times we determined that there was no hydrolysis of $\left[{ }^{14} \mathrm{C}\right]$ maltose to $\left[{ }^{14} \mathrm{C}\right]$ glucose within $30 \mathrm{~s}$, i.e. within the time course of our experiment. In other words, during a single pass through the kidney (in particular from the point of injection to the glomerulus) there is no breakdown of either maltose or trehalose to their glucose constituents. Urine did not exhibit any trehalase or maltase activity.

On the basis of these results we concluded that if there was any hydrolysis of those disaccharides to glucose, it

TABLE III

Urine Excretion of $\left[{ }^{14} \mathrm{C}\right]$ Maltose

\begin{tabular}{|c|c|c|c|c|c|c|c|}
\hline & \multirow{2}{*}{$\begin{array}{l}\text { Total }\left[{ }^{14} \mathrm{C}\right]- \\
\text { maltose } \\
\text { filtered }{ }^{*}\end{array}$} & \multirow[b]{2}{*}{$\begin{array}{l}\text { Total }{ }^{14} \mathrm{C} \\
\text { excreted }\end{array}$} & \multicolumn{2}{|c|}{ Chromatography of excreted ${ }^{14} \mathrm{C}$} & \multirow[b]{2}{*}{$\begin{array}{c}\%^{{ }^{14} \mathrm{C}} \\
\text { reabsorbed }\end{array}$} & \multirow{2}{*}{$\begin{array}{c}\%^{14} \mathrm{C} \\
\text { excreted as } \\
\text { maltose }\end{array}$} & \multirow{2}{*}{$\begin{array}{c}\%{ }^{14} \mathrm{C} \\
\text { excreted as } \\
\text { glucose }\end{array}$} \\
\hline & & & $\begin{array}{c}\% \text { as } \\
\text { maltose }\end{array}$ & $\begin{array}{c}\% \text { as } \\
\text { glucose }\end{array}$ & & & \\
\hline Control & 0.204 & 0.010 & 85 & 15 & 95 & 4 & 1 \\
\hline Phlorizin & 0.186 & 0.173 & 15 & 85 & 7 & 14 & 79 \\
\hline Phlorizin & 0.163 & 0.137 & 15 & 85 & 16 & 13 & 71 \\
\hline Control & 0.241 & 0.040 & 88 & 12 & 83 & 15 & 2 \\
\hline Phlorizin & 0.155 & 0.149 & 37 & 67 & 4 & 36 & 60 \\
\hline Maltose load & 0.138 & 0.099 & 86 & 14 & 28 & 62 & 10 \\
\hline Maltose load and phlorizin & 0.151 & 0.143 & 55 & 45 & 5 & 52 & 43 \\
\hline
\end{tabular}

* Expressed as a fraction of the amount injected into renal artery. 


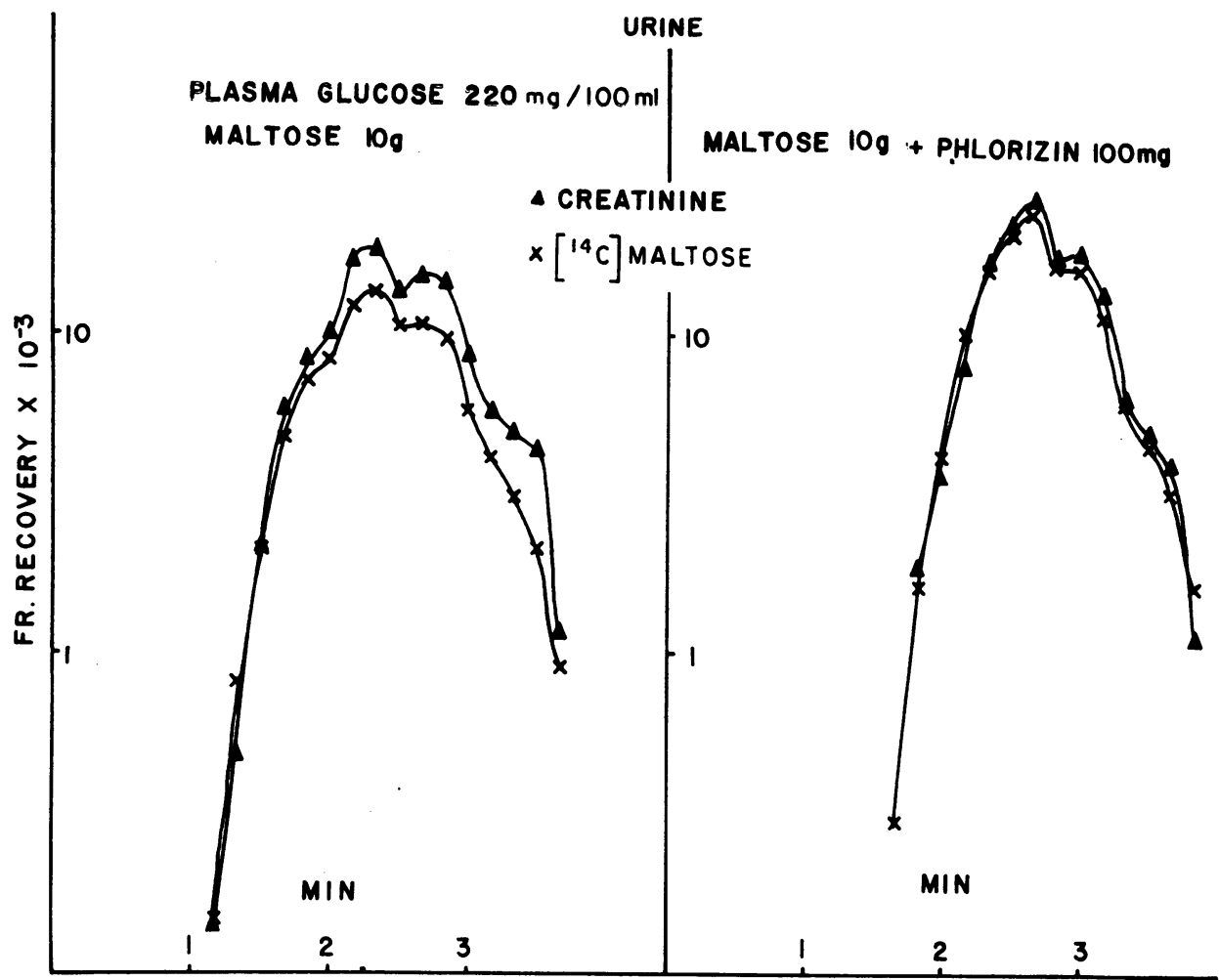

FIGURE 7 Urine outflow curves for creatinine and $\left[{ }^{14} \mathrm{C}\right]$ maltose under conditions of maltose loading and showing the effects of phlorizin.

had to be occurring somewhere between the point of filtration (glomerulus) and the site of D-glucose reabsorption (i.e. glucose $(\mathrm{G})$ receptors located along the brush border of the proximal tubule).

The experimental protocol before and after phlorizin loading was then repeated (see Figs. 5 and 6 ) but this time individual renal venous and urine samples (encompassing the peak recovery periods) were subjected to thin-layer chromatography, along with the injection solution and appropriate standards. The percentage of ${ }^{14} \mathrm{C}$ activity recovered as the monosaccharide (glucose), and disaccharide (maltose or trehalose) was determined as outlined in the Methods section. The total urine recovery of creatinine (after correcting for recirculation) is a measure of the filtration fraction and also of the total amount of ${ }^{14} \mathrm{C}$ activity filtered. Since no hydrolysis occurred in the arterial blood, the amount of ${ }^{14} \mathrm{C}$ activity filtered represents ${ }^{14} \mathrm{C}$ activity of the injected disaccharide. From the urine recovery of ${ }^{14} \mathrm{C}$ and the percentage recoverable by chromatography, the amount excreted as the monosaccharide or disaccharide can be calculated. These data are presented in Tables II and III.

The results shown in Tables II and III demonstrate that under control conditions when only a small amount of filtered ${ }^{14} \mathrm{C}$ activity is excreted in the urine, all of the recovered label is in the form of the intact disaccharide (either maltose or trehalose, depending upon what was originally injected). After the administration of phlorizin, the ${ }^{14} \mathrm{C}$ activity excreted in the urine rises to approximately $100 \%$ of that filtered. Under these conditions, ${ }^{14} \mathrm{C}$ activity roughly equivalent to the amount of label previously reabsorbed is recoverable as $\left[{ }^{14} \mathrm{C}\right]$ glucose.

Fig. 7 shows the urine results obtained when a dog was first preloaded with a large dose of unlabeled maltose, and then given an injection of tracer $\left[{ }^{14} \mathrm{C}\right]$ maltose. A second run was made following the systemic administration of $100 \mathrm{mg}$ of phlorizin. The chromatographic data for this experiment are also shown in Table III. The data indicate that maltose loading increases the fractional excretion of ${ }^{14} \mathrm{C}$ activity compared with control conditions (Fig. 4) and that all of the excreted ${ }^{14} \mathrm{C}$ label under these conditions is identifiable as the intact disaccharide. Following phlorizin administration, this ${ }^{14} \mathrm{C}$ activity in the urine rises close to $100 \%$ of that filtered and the excess excretion is now in the form of $\left[{ }^{14} \mathrm{C}\right]$ glucose. It should be noted that maltose loading increased the arterial plasma concentration of glucose from 80 to $200 \mathrm{mg} / 100 \mathrm{ml}$. This is most likely because of the glucose contaminant present in the commercially obtained maltose. The increased glucose concentration 
in this experiment cannot account for the increased urine ${ }^{14} \mathrm{C}$ excretion compared with control conditions (Table $\mathrm{I}$ ), since all of the radioactivity was recoverable only as the intact disaccharide, namely maltose.

\section{DISCUSSION}

In summary, our data show that lactose and sucrose are extracellular solutes and have no interaction with either the luminal or antiluminal nephron surfaces. In contrast, maltose and trehalose are hydrolysed somewhere between the point of filtration and the site of glucose reabsorption. Since the glomerular basement membrane does not possess $\alpha$-glucosidase activity, the disaccharidases exhibiting maltase and trehalase activity must be located in the proximal tubule brush border surface. Further, since phlorizin has no effect on the hydrolysis of $\left[{ }^{14} \mathrm{C}\right]$ maltose or $\left[{ }^{14} \mathrm{C}\right]$ trehalose to $\left[{ }^{14} \mathrm{C}\right]$ glucose but does block the transport of $\left[{ }^{14} \mathrm{C}\right]$ glucose, we infer that these disaccharidases are located in the glycocalyx region of the brush border, spatially superficial to the G transport sites which are embedded more deeply in the membrane matrix. The sites of maltase activity appear to be saturable as evidence by the decreased fractional extraction of $\left[{ }^{14} \mathrm{C}\right]$ maltose under conditions of maltose loading and the consequent increased urine excretion of ${ }^{14} \mathrm{C}$ radioactivity, chromatographically identifiable as the intact disaccharide.

Our findings in vivo, for trehalase and maltase localization in dog kidney, agree with the enzymatic content in isolated brush border membranes from rat kidney $(5,16,17)$. Treatment of these brush border fragments from rat kidney with papain or trypsin, results in differential release of maltase, trehalase, aminopeptidase, and alkaline phosphatase into the supernate. The effect of the in vitro solubilization procedures on the functional integrity of glucose transport receptors, however, is unsettled (see references 16 and 17 ), so that it is impossible to tell from these in vitro studies whether the disaccharidases are superficial to the glucose transporters. In contrast, our in vivo data definitely localize trehalase as well as maltase to the glycocalyx region superficial to the glucose transport system. Thus the experimental findings showing that papain digestion releases maltase but not trehalase from membrane preparations (3) is probably a reflection of the structural organization of these enzymes within the membrane, with respect to each other, and has little to do with their relationship to the glucose transport mechanism.

What about the presence of disaccharidases internal (i.e. serosal) to the brush border surface? Although we have no information from our experiments about the localization of $\alpha$-glucosidases within the cell interior, we can make certain deductions about the presence of these enzymes at the antiluminal (basal and lateral) surface of the nephron.

The fact that the renal vein outflow curves for maltose and trehalose are almost superimposable on the transit pattern for creatinine, indicates that the disaccharides have an extracellular distribution from the postglomerular circulation. We infer that the disaccharides have no interaction with the antiluminal surface of the nephron, and consequently, that there is no disaccharidase activity internal to the glucose $(G)$ transport receptors. These conclusions are supported by the in vitro data of $R$. Kinne ${ }^{1}$ showing that a purified membrane fraction derived from the basal and lateral membranes of proximal tubule cells does not possess maltase activity.

In view of the foregoing discussion there seems to be no evidence in support of a role for trehalase in the renal transport of glucose.

Based on earlier investigations $(12,13,18)$ certain chemical and steric requirements were postulated to account for the specificity exhibited by the brush border and basal surface of the renal tubule with regard to monosaccharide transport in dog kidney. By carrying out competitive inhibition experiments using phlorizin, mannose, and glucose loading, it was shown that each of the seven monosaccharides which were found to interact with the brush border could be divided into one of two groups. Six substances including $\alpha$ - and $\beta$-methylD-glucoside, D-fructose, D-galactose, and 2-deoxy-D-glucose share what we have called the $\mathrm{G}$ or glucose receptor, while the $M$ receptor has mannose as the preferred substrate. Since disaccharides composed of two glucose molecules, e.g. maltose (1- $\alpha-4$ glycosidic linkage) or trehalose (1- $\alpha-1$ glycosidic linkage) possess all of the chemical and steric requirements of the $G$ receptor, the only limiting factor governing their interaction with the transport receptors is size (19). (Contrast a molecular radius for sucrose of $5.5 \AA$ compared to glucose of $4.4 \AA$ ). The fact that neither maltose nor trehalose is reabsorbed in any detectable quantity as the intact disaccharide is best explained by assuming that either the receptor excludes the disaccharide or else that there are steric hindrances within the binding site.

In the hamster intestine it has been found (20) that glucose released as a consequence of disaccharidase activity is transported by a pathway different $\left(\mathrm{Na}^{+}\right.$independent) from the usual glucose transport system. The existence of a similar transport pathway in the kidney cannot be excluded. However, if such a transport system exists, its phlorizin sensitivity appears to be identical to that of the $G$ transport receptor.

If the renal brush border disaccharidases are not involved directly in glucose transport then there is some

${ }^{1}$ Personal communication. 
justification for questioning their functional significance in mammalian kidney. It is possible that renal disaccharidases in man parallel the intestinal disaccharidase activities. A clinical association has already been reported between intestinal sucrase-isomaltase deficiency states and renal calculi (21). It might also be postulated that inherited or acquired intestinal disaccharidase deficiency states could be accompanied by similar deficiencies in kidney $\alpha$-glucosidases. In a recent study of the metabolism of circulating maltose in man, only $3 \%$ of an administered maltose load was excreted in the urine either as maltose or glucose (22). Extrapolating from our present study on dogs, the low urine excretion of maltose is probably the result of the hydrolysis of filtered maltose along the proximal tubule brush border and subsequent reabsorption as glucose.

Despite the fact that their occurrence could be simply vestigial in man, the presence of $\alpha$-glucosidases in renal tubular membranes provide useful membrane markers for in vitro studies and serve to emphasize the structural and functional similarities between intestinal and renal epithelia.

\section{ACKNOWLEDGMENTS}

The author is indebted to Judith Black and Alice Chatzilias for their excellent technical assistance. This work was supported by the Medical Research Council Grant MA-4590 and the Atkinson Charitable Foundation (Toronto). The purchase of a Technicon AutoAnalyzer was made possible through the generosity of the J. P. Bickell Foundation (Toronto).

\section{REFERENCES}

1. Silverman, M. 1972. The localization of disaccharidases in relation to sugar transport receptors in dog kidney. Clin. Res. 20: 962.

2. Berger, S. J., and B. Sacktor. 1970. Preparation and biochemical characterization of brush borders from rabbit kidney. J. Cell Biol. $47: 637$.

3. Stevenson, F. K. 1972. The disaccharidase activity of a membrane fraction obtained from the rabbit renal cortex, Biochim. Biophys. Acta. 266: 144.

4. Chertok, R. J., and S. Lake. 1972. A simple method for the preparation of renal brush borders. J. Cell Biol. 54: 426.

5. Glossmann, H., and D. M. Neville, Jr. 1972. $\gamma$-Glutamyltransferase in kidney brush border membranes. FEBS Lett. 19 : $4: 340$.

6. Sacktor, B. 1968. Trehalase and the transport of glucose in the mammalian kidney and intestine. Proc. Natl. Acad.Sci. U.S. A. $60: 1007$.
7. Miller, D., and Robert R. Crane. 1961. The digestive function of the epithelium of the small intestine. I. An intracellular locus of disaccharide and sugar phosphate ester hydrolysis. Biochim. Biophys. Acta. 52: 281.

8. Miller, D., and R. R. Crane. 1961. The digestive function of the epithelium of the small intestine. II. Localization of disaccharide hydrolysis in the isolated brush border portion of the intestinal epithelial cells. Biochim. Biophys. Acta. 52: 293.

9. Malathi, P., and R. K. Crane. 1968. Spatial relationship between intestinal disaccharidases and the active transport system for sugars. Biochim. Biophys. Acta. 163: 275.

10. Semenza, G., and L. Rikova. 1969. Allosteric effects and phlorizin inhibition of intestinal trehalase. Biochim. Biophys. Acta. 178: 393.

11. Sacktor, B., and N. C. Wu. 1971. Studies on the spatial relationship between intestinal disaccharidases and the phlorizin-sensitive transport of glucose. Arch Biochem. Biophys. 144: 423 .

12. Silverman, M., M. A. Aganon, and F. P. Chinard. 1970. D-Glucose interactions with renal tubule surfaces. Am. J. Physiol. 218: 735.

13. Silverman, M., M. A. Aganon, and F. P. Chinard. 1970. Specificity of monasaccharide transport in dog kidney. Am. J. Physiol. 218: 743.

14. Chinard, F. P., W. R. Taylor, F. Nolan, and T. Enns. 1959. Renal handling of glucose in dogs. Am. J. Physiol. 196: 535.

15. Walker, A. M., P. A. Bott, J. Oliver, and M. C. MacDowell. 1941. The collection and analysis of fluid from single nephrons of the mammalian kidney. $\mathrm{Am} . \mathrm{J}$. Physiol. 134: 580.

16. Thomas, L., and R. Kinne. 1972. Studies on the arrangement of a glucose sensitive phlorizin binding site in the microvilli of isolated rat kidney brush border. FEBS Lett. 25: $2: 42$.

17. Glossman, H., and D. M. Neville, Jr. 1972. Phlorizin receptors in isolated brush border membranes. J. Biol. Chem. 247: 7779.

18. Silverman, M. 1971. The specificity of transport receptors for monosaccharides in the dog kidney. Clin. Res. $19: 812$.

19. Longsworth, L. G. 1953. Diffusion measurements, at $25^{\circ} \mathrm{C}$, of aqueous solutions of amino acids, peptides, and sugars. J. Am. Chem. Soc. 75: 5705.

20. Caspary, W. F. 1972. On the mechanism of absorption of glucose from disaccharides in hamster small intestine. Hoppe-Seyler's Z. Physiol. Chem. 353: 5.

21. Starnes, C. W., and J. D. Welsh. 1970. Intestinal sucrase-maltase deficiency and renal calculi. N. Engl. J. Med. 282: 1023.

22. Young, Sister J. M., and E. Weser. 1971. The metabolism of circulating maltose in man. J. Clin. Invest. 50: 986. 